\title{
Effect of Eicosapentaenoic Acid and Docosahexaenoic Acid in Pollock Liver Oil on Growth and Fatty Acid Composition of Rainbow Trout*1
}

\author{
Toshio TAKeUCHI ${ }^{* 2}$ and Takeshi WaTANABE*2 \\ (Received February 16, 1977)
}

\begin{abstract}
A feeding experiment was conducted to compare the effects of eicosapentaenoic acid $(20: 5 \omega 3)$ and docosahexaenoic acid $(22: 6 \omega 3)$ with that of linolenic acid $(18: 3 \omega 3)$ on growth and fatty acid composition of rainbow trout.

The growth rate was much reduced in fish kept on a diet containing $0.5 \% 18: 3 \omega 3$. The replacement of $0.5 \% 18: 3 \omega 3$ with either $0.5 \% 20: 5 \omega 3$ or $0.5 \% 22: 6 \omega 3$ markedly increased the growth rate. This result indicates that 20:503 has the same growth enhancing effect as

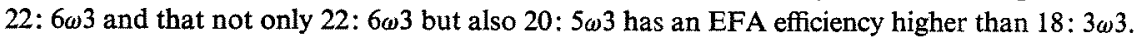
The best weight gain was obtained in fish on a diet containing $0.25 \%$ of each of $20: 5 \omega 3$ and 22: $6 \omega 3$ respectively, indicating an additive effect between $20: 5 \omega 3$ and 22: $6 \omega 3$ on the growth of rainbow trout. The ratio of 20:3 $\omega 9$ to 22: $6 \omega 3$ in livers, an EFA index of rainbow trout, appeared as a low value, $0.4-0.5$, in the fish fed diets containing either $20: 5 \omega 3$ or $22: 6 \omega 3$. This indicates a nearly normal EFA status, whereas the ratio of the fish receiving $0.5 \%$ 18: $3 \omega 3$ was 0.8 , which indicates an insufficient EFA status.

Thus it has been demonstrated that both $20: 5 \omega 3$ and $22: 6 \omega 3$ have a biological efficiency or an EFA efficiency higher than that of $18: 3 \omega 3$ and that the growth enhancing effect of pollock liver oil is due to an additive effect between $20: 5 \omega 3$ and 22:6 63 in its fatty acid fraction.
\end{abstract}

From studies reported in this series of papers, ${ }^{1,2)}$ it has become apparent that pollock liver oil is superior to other fats in promoting the growth of rainbow trout, and that the fatty acids, especially the highly unsaturated $\omega 3$ fatty acids such as $20: 5 \omega 3$ (eicosapentaenoic acid) and 22: $6 \omega 3$ (docosahexaenoic acid), are the principal factor in the nutritive value of dietary pollock liver oil. In addition, we demonstrated that rainbow trout responded better to dietary $22: 6 \omega 3$, one of the effective components in the pollock liver

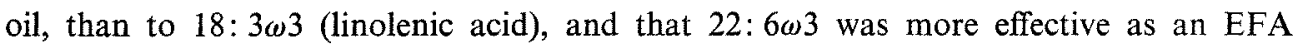
(essential fatty acid) than $18: 3 \omega 3$. However, it still remains unknown whether $20: 5 \omega 3$, another effective component in the liver oil, has the same growth enhancing effect as 22: $6 \omega 3$ and also has an EFA value higher than 18:3 $\omega 3$. This study was conducted to compare the effects of $20: 5 \omega 3$ and $22: 6 \omega 3$ with that of $18: 3 \omega 3$ on growth and fatty acid composition of rainbow trout, and moreover to clarify whether there is an additive effect on growth of rainbow trout between 20:5 3 and $22: 6 \omega 3$ in the pollock liver oil. A comparison of growth effect was also made between these fatty acids and HUFA (highly

*1 Studies on Nutritive Value of Dietary Lipids in Fish-X.

*2 Laboratory of Fish Nutrition, Tokyo University of Fisheries, Konan, Minato-ku, Tokyo (竹内俊郎・渡辺 武: 束京水産大学). 
unsaturated $\omega 3$ fatty acids), a mixture of $20: 5 \omega 3$ and $22: 6 \omega 3(1: 1)$ prepared from cuttlefish liver oil.

\section{Materials and Methods}

The composition of the basal diet, the method of diet preparation, a preliminary feeding with a casein diet, and general feeding techniques were the same as those described in the previous paper. ${ }^{3}$. The purity of methyl laurate (12:0) obtained from Tokyo Chemical Industry Co. Ltd., methyl linolenate (18:3w3) from Sigma Chemical Co., and methyl docosahexaenoate $(22: 6 \omega 3)$ from Nu-Chek-Prep was checked by gas-liquid chromatography (GLC), and found to be $99.9,99.9$ and $93.8 \%$, respectively. Methyl esters of HUFA were prepared from cuttlefish liver oil by the same procedures described previously ${ }^{2}$, and contained $36.8 \% 20: 5 \omega 3$ and $36.9 \% 22: 6 \omega 3$. The source of eicosapentaenoic acid 20:5 33 was the oil extracted with chloroform-methanol $(2: 1)^{4)}$ from rotifers Brachionus plicatilis cultured with marine chlorella Chlorella minutissima. The oil contained 25\% 20:5 53 which had been incorporated from the marine chlorella. A concentrate of the methyl ester of $20: 5 \omega 3$ was prepared from the oil by saponification, esterification, and by urea inclusion, ${ }^{5}$ ) followed by vaccuum distillation. The final product, as analysed by GLC, contained $71.4 \% 20: 5 \omega 3,2.4 \% 20: 3 \omega 6,15.3 \% 20: 4 \omega 6$, $1.0 \% 22: 5 \omega 3$ and $5.4 \%$ other fatty acids. The proportions of dietary fats were adjusted so that when added to the diets these incorporated exactly equal amounts of the desired component (Table 1).

Table 1. Compositions of dietary lipids

\begin{tabular}{ccc} 
Diet no. & Dietary lipid & Total $\omega 6 \%$ \\
\hline 1 & $4.5 \%$ Methyl laurate $+0.5 \%$ Methyl linolenate & $\operatorname{tr}$ \\
2 & $4.5 \%$ Methyl laurate $+0.5 \%$ Methyl eicosapentaenoate & 0.13 \\
3 & $4.5 \%$ Methyl laurate $+0.5 \%$ Methyl docosahexaenoate & 0.03 \\
4 & $4.5 \%$ Methyl laurate $+\left\{\begin{array}{l}0.25 \% \text { Methyl eicosapentaenoate } \\
0.25 \% \text { Methyl docosapexaenoate }\end{array}\right.$ & 0.08 \\
5 & $4.5 \%$ Methyl laurate $+0.5 \% \omega 3$ highly unsaturated fatty acid mixture* (HUFA) & 0.03 \\
\hline $20: 5 \omega 3: 22: 6 \omega 3=1: 1$ &
\end{tabular}

Rainbow trout Salmo gairdneri weighing $2.1 \mathrm{~g}$ in body weight were used as the experimental animals. They were fed a fat-free diet for 3 weeks before the initiation of feeding experiment, and then randomly divided into lots of 25 fish. Each experimental group was fed one of the variety of diets containing different dietary $\omega 3$ fatty acid methyl esters as shown in Table 1 for a 14-week period. The water temperature was maintained at $16^{\circ} \mathrm{C} \pm 2{ }^{\circ} \mathrm{C}$ throughout the feeding period.

Comparisons of the growth effect of each $\omega 3$ fatty acid methyl ester were made at the $0.5 \%$ dietary level to save materials, and also for the reason that supplemental effects 
of $0.5 \% 22: 6 \omega 3$ and $0.5 \%$ HUFA on the growth of rainbow trout were comparable to that of $1 \% 18: 3 \omega 3$ which satisfies the EFA requirement of the fish. ${ }^{2}$ Diet 4 was a modification of diet 5 in which $0.25 \% 20: 5 \omega 3$ and $0.25 \% 22: 6 \omega 3$ were added individually

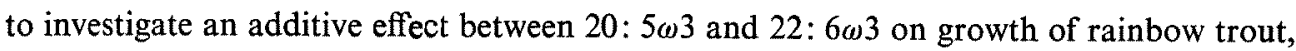
and should have had almost the same fatty acid composition as diet 5 .

At the end of the feeding trial, all fish were taken from each lot and pooled for extraction of lipids from livers and brains. Analytical procedures such as separation of polar and nonpolar lipids, isolation of triglycerides from nonpolar lipids, preparation of methyl esters, and GLC operating conditions were all the same as those described in the previous papers $^{1,2)}$.

\section{Results and Discussion}

Results of the feeding experiment The effects of different dietary $\omega 3$ fatty acids on growth rate, feed conversion and hepatosomatic index are summarized in Table 2 and

Table 2. Results of 14 weeks of the feeding experiment

\begin{tabular}{ccccccc}
\hline \multirow{2}{*}{ Diet no. $\begin{array}{c}\text { Number } \\
\text { of } \\
\text { fish }\end{array}$} & \multicolumn{2}{c}{ Av body wt (g) } & & $\begin{array}{c}\text { Percent } \\
\text { gain }\end{array}$ & $\begin{array}{c}\text { Feed } \\
\text { conversion }\end{array}$ & $\begin{array}{c}\text { Hepato- } \\
\text { somatic } \\
\text { index }\end{array}$ \\
\cline { 2 - 4 } & 25 & 2.1 & 11.9 & 466.7 & 1.18 & 2.4 \\
2 & 25 & 2.1 & 15.5 & 638.1 & 1.26 & 2.2 \\
3 & 25 & 2.1 & 15.0 & 614.3 & 1.27 & 2.4 \\
4 & 25 & 2.1 & 16.5 & 685.7 & 1.23 & 2.4 \\
5 & 25 & 2.1 & 16.4 & 681.0 & 1.26 & 2.4 \\
\hline
\end{tabular}

growth curves of individual group are plotted in Fig. 1.

There was no mortality of the experimental fish throughout the feeding period. The growth rate was much reduced in fish kept on diet 1 containing $0.5 \%$ methyl linolenate. The replacement of $0.5 \%$ linolenate with either $0.5 \%$ eicosapentaenoate (diet 2) or $0.5 \%$ docosahexaenoate (diet 3 ) markedly increased the growth rate. In the previous work $^{21}$ we demonstrated that rainbow trout responded better to dietary $22: 6 \omega 3$ and HUFA than to $18: 3 \omega 3$, and that $22: 6 \omega 3$ and HUFA were more effective as EFA than 18: $3 \omega 3$. The present result also clearly indicates that $20: 5 \omega 3$ has the same growth en-

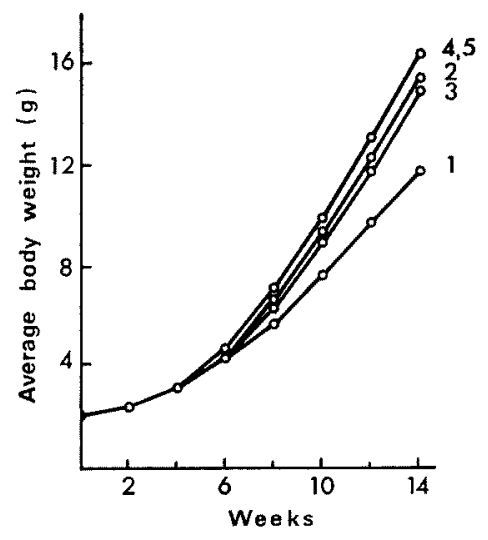

Fig. 1. Effect of dietary methyl esters of $\omega 3$ fatty acids on growth rate of rainbow trout. Curves 1, 2, 3, 4, and 5, 4.5\% methyl laurate diet containing $0.5 \%$ methyl linolenate, $0.5 \%$ methyl eicosapentaenoate, $0.5 \%$ methyl docosahexaenoate, $0.25 \%$ methyl eicosapentaenoate plus $0.25 \%$ methyl docosahexaenoate, and $0.5 \%$ HUFA, respectively. 
hancing effect as $22: 6 \omega 3$ and that not only $22: 6 \omega 3$ but also $20: 5 \omega 3$ has an EFA efficiency

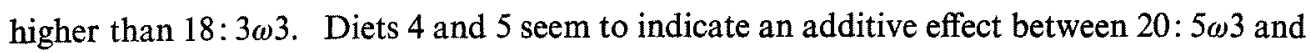
22: $6 \omega 3$ on the growth of rainbow trout. The best weight gain was obtained in fish on diet 4 containing $0.25 \%$ of each of $20: 5 \omega 3$ and $22: 6 \omega 3$ respectively. The growth rate of fish receiving diet 5 was also comparable to that of the fish on diet 4 , a quite reasonable result since both diets contained almost the same dietary fatty acids. Each dietary $\omega 3$ fatty acid except 18:3 33 contained small amounts of $\mathrm{C}_{20}<\omega 6$ fatty acids as impurities, however the $\omega 6$ acids at these levels seemed to exert no significant effect on growth of rainbow trout judging from the feeding result. These results, together with the fact that the pollock liver oil contains only a trace amount of $\mathrm{C}_{20}<\omega 6$ fatty acids, support our hypothesis, described in the preceding paper, ${ }^{2)}$ that the growth-enhancing effect of highly unsaturated fatty acids in pollock liver oil is probably due to an additive effect between 20: $5 \omega 3$ and 22: $6 \omega 3$.

There were no differences in feed conversion and hepatosomatic index, although feed conversion was slightly lower in fish fed diet 1 containing $0.5 \% 18: 3 \omega 3$.

Lipid compositions and fatty acid compositions of liver and brain lipids The lipid composition of the livers and brains is presented in Table 3. The fish receiving diet 1 containing $0.5 \% 18: 3 \omega 3$ show a high content of liver lipid, and an accumulation of nonpolar lipids in the liver, indicating that the fish were receiving an insufficient amount of $18: 3 \omega 3$. On the other hand, those receiving the diets containing equal amounts of the other $\omega 3$ fatty acids show lower lipid contents in the livers. This result agrees with

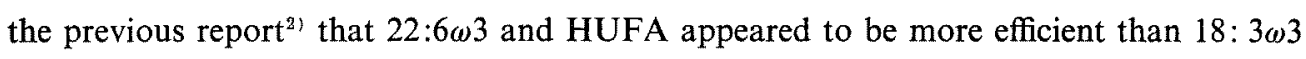
in reducing the level of liver lipid. There were however no marked changes in the lipid composition of brain due to the difference of dietary $\omega 3$ fatty acids.

Table 3. Effect of dietary lipids on lipid compositions of the liver and brain

\begin{tabular}{|c|c|c|c|c|c|c|c|c|c|c|}
\hline \multirow{2}{*}{ Diet no. } & \multicolumn{3}{|c|}{$\%$ in Liver } & \multicolumn{2}{|c|}{$\%$ in Liver lipid } & \multicolumn{3}{|c|}{$\%$ in Brain } & \multicolumn{2}{|c|}{$\%$ in Brain lipid } \\
\hline & $\begin{array}{l}\text { Total } \\
\text { lipid }\end{array}$ & Polar & $\begin{array}{l}\text { Non- } \\
\text { polar }\end{array}$ & Polar & $\begin{array}{l}\text { Non- } \\
\text { polar }\end{array}$ & $\begin{array}{l}\text { Total } \\
\text { lipid }\end{array}$ & Polar & $\begin{array}{l}\text { Non- } \\
\text { polar }\end{array}$ & Polar & $\begin{array}{l}\text { Non- } \\
\text { polar }\end{array}$ \\
\hline 1 & 9.3 & 2.7 & 6.6 & 29.4 & 70.6 & 6.1 & 4.0 & 2.1 & 65.9 & 34.1 \\
\hline 2 & 4.9 & 3.0 & 1.9 & 62.0 & 38.0 & 5.9 & 3.7 & 2.2 & 63.3 & 36.7 \\
\hline 3 & 5.7 & 3.0 & 2.7 & 53.1 & 46.9 & 5.8 & 3.7 & 2.1 & 63.4 & 36.6 \\
\hline 4 & 5.2 & 2.9 & 2.2 & 56.9 & 43.1 & 5.7 & 4.0 & 1.7 & 69.3 & 30.7 \\
\hline 5 & 5.3 & 2.8 & 2.5 & 52.7 & 47.3 & 5.7 & 4.0 & 1.7 & 70.3 & 29.7 \\
\hline
\end{tabular}

The fatty acid compositions of total, triglyceride and polar lipid fractions are shown in Tables 4 and 5, respectively. When comparing the triglyceride fraction with the polar lipid fraction, the percentage of $18: 1$ was generally higher in the former, while as observed

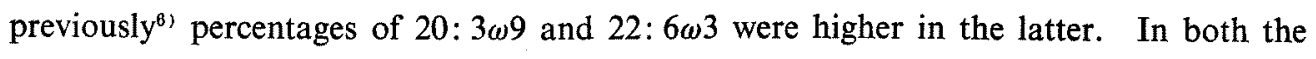
liver and brain lipids there were no significant differences in fatty acid composition, as in 
Table 4. Fatty acid compositions of total, triglyceride (TG) and polar lipid fractions from the liver (area \%)

\begin{tabular}{|c|c|c|c|c|c|c|c|c|c|c|c|c|c|c|c|}
\hline \multirow{3}{*}{$\begin{array}{l}\text { Fatty } \\
\text { acid }\end{array}$} & \multicolumn{15}{|c|}{ Diet no. } \\
\hline & \multicolumn{3}{|c|}{1} & \multicolumn{3}{|c|}{2} & \multicolumn{3}{|c|}{3} & \multicolumn{3}{|c|}{4} & \multicolumn{3}{|c|}{5} \\
\hline & Total & Polar & TG & Total & Polar & TG & Total & Polar & TG & Total & Polar & TG & Total & Polar & TG \\
\hline $12: 0$ & 0.4 & 0.1 & 0.5 & 0.4 & 0.1 & 1.2 & 0.4 & 0.1 & 1.0 & 0.3 & 0.1 & 0.9 & 0.5 & 0.1 & 0.6 \\
\hline $14: 0$ & 3.0 & 1.8 & 3.3 & 2.9 & 1.7 & 3.1 & 3.0 & 1.7 & 4.8 & 2.5 & 1.8 & 3.3 & 3.0 & 1.9 & 3.3 \\
\hline $16: 0$ & 12.2 & 15.5 & 14.1 & 16.8 & 17.0 & 16.1 & 15.5 & 16.0 & 17.3 & 13.2 & 15.5 & 15.3 & 14.4 & 17.7 & 16.8 \\
\hline $16: 1$ & 13.7 & 8.0 & 13.7 & 12.6 & 8.3 & 10.5 & 13.2 & 8.2 & 15.5 & 10.5 & 8.6 & 10.7 & 13.8 & 9.0 & 12.0 \\
\hline $18: 0$ & 4.7 & 5.2 & 5.5 & 4.4 & 5.2 & 4.9 & 4.6 & 5.1 & 5.4 & 4.6 & 5.1 & 5.5 & 4.6 & 5.4 & 6.3 \\
\hline $18: 1$ & 50.5 & 29.0 & 57.3 & 32.8 & 25.0 & 50.4 & 38.2 & 25.0 & 48.7 & 39.2 & 24.3 & 54.8 & 38.2 & 26.1 & 51.4 \\
\hline $18: 2 \omega 6$ & 0.8 & 2.0 & 0.6 & 1.1 & 1.1 & 0.7 & 1.1 & 1.1 & 0.7 & 1.0 & 1.0 & 0.5 & 1.1 & 1.2 & 0.7 \\
\hline $18: 3 \omega 3$ & 0.2 & 0.5 & 0.1 & 0.1 & 0.1 & 0.1 & 0.1 & 0.1 & 0.1 & 0.1 & 0.1 & 0.1 & 0.1 & 0.2 & 0.1 \\
\hline $\left.\begin{array}{l}18: 4 \omega 3 \\
20: 0\end{array}\right\}$ & 0.2 & 0.3 & 0.1 & 0.1 & 0.1 & 0.2 & 0.1 & 0.2 & 0.2 & 0.1 & 0.2 & 0.2 & 0.1 & 0.1 & 0.1 \\
\hline $20: 1$ & 3.1 & 4.3 & 2.8 & 3.4 & 3.8 & 6.3 & 3.3 & 3.9 & 2.7 & 3.8 & 4.1 & 4.4 & 3.4 & 3.9 & 4.3 \\
\hline $20: 2 \omega 9$ & 1.5 & 2.6 & 0.9 & 1.6 & 2.5 & 2.1 & 1.8 & 2.7 & 0.8 & 1.8 & 2.5 & 1.2 & 1.9 & 2.6 & 1.5 \\
\hline $\left.\begin{array}{l}20: 3 \omega 9 \\
20: 2 \omega 6\end{array}\right\}$ & 2.7 & 9.9 & 0.2 & 5.1 & 8.3 & 0.7 & 4.9 & 10.1 & 0.2 & 5.8 & 10,0 & 0.3 & 4.2 & 8.0 & 0.4 \\
\hline $20: 3 \omega 6$ & 0.2 & 1.1 & $\operatorname{tr}$ & 0.6 & 1.0 & 0.1 & 0.4 & 1.0 & $\operatorname{tr}$ & 0.5 & 1.0 & $\operatorname{tr}$ & 0.3 & 0.7 & $\operatorname{tr}$ \\
\hline $\left.\begin{array}{l}20: 4 \omega 6 \\
20: 3 \omega 3\end{array}\right\}$ & 0.2 & 0.6 & 0.1 & 1.6 & 2.3 & 0.3 & 0.3 & 1.0 & 0.2 & 0.9 & 1.4 & 0.2 & 0.6 & 1.0 & 0.1 \\
\hline $20: 4 \omega 3$ & 0.2 & 0.5 & $\operatorname{tr}$ & 0.1 & 0.2 & 0.1 & $\operatorname{tr}$ & 0.1 & 0.2 & 0.1 & 0.2 & 0.2 & $\operatorname{tr}$ & 0.2 & 0.1 \\
\hline $20: 5 \omega 3$ & 0.9 & 1.0 & 0.3 & 0.7 & 1.0 & 0.7 & 0.3 & 0.4 & 0.8 & 0.5 & 0.6 & 1.0 & 1.1 & 0.9 & 0.9 \\
\hline $22: 1$ & 0.9 & 0.3 & 0.3 & 0.3 & 0.3 & 1.0 & 0.3 & 0.2 & 0.3 & 0.5 & 0.2 & 0.6 & 0.7 & 0.7 & 0.6 \\
\hline $22: 4 \omega 9$ & 0.1 & 0.7 & - & 0.3 & 0.5 & - & 0.4 & 0.9 & - & 0.3 & 0.6 & - & 0.3 & 0.8 & - \\
\hline $22: 4 \omega 6$ & $\operatorname{tr}$ & 0.3 & 一 & 0.3 & 0.4 & - & 0.2 & 0.4 & - & 0.2 & 0.4 & - & 0.2 & 0.4 & - \\
\hline $22: 5 \omega 6$ & $\operatorname{tr}$ & 0.4 & - & 1.0 & 1.4 & - & 0.3 & 0.6 & - & 0.6 & 0.9 & - & 0.4 & 0.9 & - \\
\hline $22: 5 \omega 3$ & 0.2 & 0.8 & - & 0.5 & 0.8 & - & 0.2 & 0.3 & - & 0.4 & 0.4 & - & 0.3 & 0.3 & - \\
\hline $22: 6 \omega 3$ & 3.3 & 12.6 & $\operatorname{tr}$ & 12.0 & 16.7 & 0.5 & 10.4 & 19.0 & 0.7 & 11.9 & 18.5 & 0.6 & 9.8 & 15.5 & 0.5 \\
\hline $\begin{array}{l}20: 3 \omega 9 / \\
22: 6 \omega 3\end{array}$ & 0.8 & 0.8 & I & 0.4 & 0.5 & / & 0.5 & 0.5 & I & 0.5 & 0.5 & I & 0.4 & 0.5 & $\nearrow$ \\
\hline
\end{tabular}


Table 5. Fatty acid compositions of triglyceride (TG) and polar lipid fractions from the brain (area \%)

\begin{tabular}{|c|c|c|c|c|c|c|c|c|c|c|}
\hline \multirow{3}{*}{ Fatty acid } & \multicolumn{10}{|c|}{ Diet no. } \\
\hline & \multicolumn{2}{|c|}{1} & \multicolumn{2}{|c|}{2} & \multicolumn{2}{|c|}{3} & \multicolumn{2}{|c|}{4} & \multicolumn{2}{|c|}{5} \\
\hline & Polar & $\mathrm{TG}$ & Polar & $\mathrm{TG}$ & Polar & $\mathrm{TG}$ & Polar & $\mathrm{TG}$ & Polar & $\mathrm{TG}$ \\
\hline $12: 0$ & 0.5 & 6.5 & 0.6 & 5.9 & 0.6 & 5.1 & 0.6 & 5.5 & 0.4 & 5.9 \\
\hline $14: 0$ & 1.0 & 5.6 & 0.8 & 4.1 & 0.7 & 4.1 & 0.7 & 4.2 & 0.8 & 4.2 \\
\hline $16: 0$ & 15.9 & 18.4 & 18.4 & 18.7 & 19.7 & 18.9 & 19.7 & 19.2 & 19.6 & 21.0 \\
\hline $16: 1$ & 10.2 & 13.9 & 8.4 & 13.8 & 8.2 & 14.7 & 8.3 & 14.3 & 7.6 & 14.3 \\
\hline $18: 0$ & 6.7 & 2.9 & 7.3 & 4.3 & 7.0 & 4.0 & 6.8 & 4.6 & 7.0 & 4.4 \\
\hline $18: 1$ & 29.8 & 27.9 & 27.2 & 34.2 & 29.6 & 37.2 & 28.1 & 36.4 & 30.1 & 35.1 \\
\hline $18: 2 \omega 6$ & 1.1 & 2.1 & 1.0 & 1.4 & 1.0 & 1.3 & 0.9 & 1.1 & 1.0 & 1.3 \\
\hline $18: 3 \omega 3$ & 0.2 & 2.7 & 0.1 & 0.6 & 0.1 & 0.3 & 0.1 & 0.4 & 0.1 & 0.3 \\
\hline $\left.\begin{array}{l}\text { 18: } 4 \omega^{3} \\
20: 0\end{array}\right\}$ & 0.3 & 1.4 & 0.1 & 0.6 & 0.1 & 0.4 & 0.2 & 0.5 & 0.1 & 0.4 \\
\hline $20: 1$ & 3.5 & 1.6 & 3.7 & 3.5 & 3.4 & 3.3 & 3.4 & 3.9 & 3.3 & 3.2 \\
\hline $20: 2 \omega 9$ & 1.5 & 1.9 & 1.1 & 1.4 & 1.0 & 1.1 & 1.0 & 1.3 & 1.0 & 1.1 \\
\hline $\left.\begin{array}{l}20: 3 \omega 9 \\
20: 2 \omega 6\end{array}\right\}$ & 2.1 & 0.3 & 1.2 & 0.4 & 1.4 & 0.3 & 1.3 & 0.4 & 1.2 & 0.2 \\
\hline $\left.\begin{array}{l}20: 4 \omega 6 \\
20: 3 \omega 3\end{array}\right\}$ & 0.8 & 0.8 & 1.5 & 0.7 & 0.7 & 0.3 & 1.1 & 0.4 & 0.9 & 0.4 \\
\hline $20: 4 \omega 3$ & 0.5 & 1.3 & $\operatorname{tr}$ & 0.5 & $\operatorname{tr}$ & 0.5 & $\operatorname{tr}$ & 0.6 & 0.1 & 0.3 \\
\hline $\left.\begin{array}{l}20: 5 \omega 3 \\
22: 1^{3}\end{array}\right\}$ & 2.0 & 9.5 & 1.8 & 5.9 & 1.4 & 3.8 & 1.6 & 3.2 & 1.5 & 3.2 \\
\hline $22: 5 \omega 6$ & 0.4 & $\operatorname{tr}$ & 0.6 & $\operatorname{tr}$ & 0.3 & $\operatorname{tr}$ & 0.8 & $\operatorname{tr}$ & 0.3 & $\operatorname{tr}$ \\
\hline $22: 5 \omega 3$ & 1.0 & 0.7 & 1.3 & 0.5 & 0.8 & $\operatorname{tr}$ & 1.3 & - & 1.3 & 0.7 \\
\hline $22: 6 \omega 3$ & 18.5 & 0.5 & 21.4 & 1.8 & 21.1 & 3.0 & 21.6 & 2.3 & 21.3 & 2.6 \\
\hline
\end{tabular}

this experiment fish were fed diets containing almost the same kind of dietary $\omega 3$ fatty acids except fish on diet 1 which contained $0.5 \%$ linolenate. In the fish receiving diet 1

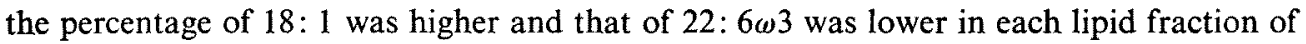

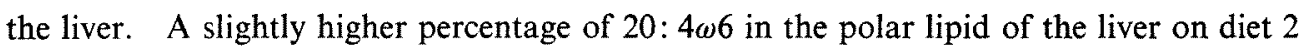

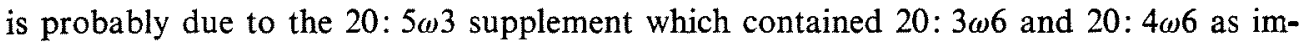
purities. In the same tissue dietary $20: 5 \omega 3$ elevated the concentration of $22: 6 \omega 3$, which kept the concentration of $20: 5 \omega 3$ low. This fact indicates that most of the dietary $\omega 3$ fatty acids, including 20:5 23 , are converted to $22: 6 \omega 3$, and as suggested in the previous paper $^{2)}$ very little is deposited unaltered in the liver of rainbow trout. A similar result

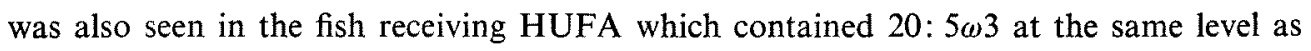
$22: 6 \omega 3$.

The ratio of $20: 3 \omega 9$ to $22: 6 \omega 3$ in livers, an EFA index of rainbow trout, appeared as a low value, $0.4-0.5$, in the fish fed diets containing either $20: 5 \omega 3$ or $22: 6 \omega 3$. This indicates a nearly normal status, whereas the ratio of the fish receiving $0.5 \% 18: 3 \omega 3$ was

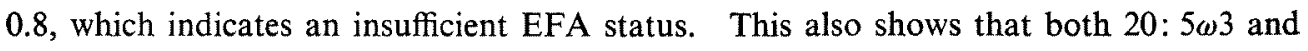
22: $6 \omega 3$, and also HUFA, are more effective as EFA than is 18:3 33 . The ratio observed in the total lipid fractions is almost the same as that in the polar lipid fractions. This 
suggests that the ratio in either fraction can be used for the EFA index in rainbow trout fingerlings.

The fatty acids of the brain lipid are not as much affected by dietary fatty acids as are those of the liver lipid. A similar result was obtained in the brain lipid of fish fed an EFA-deficient diet*.

In the studies of this series, it has been demonstrated that pollock liver oil is a superior food for the promotion of growth in rainbow trout, and that the growth-enhancing effect

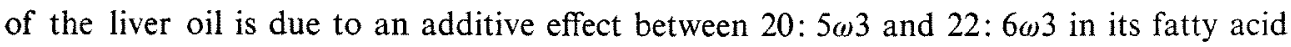
fraction. In addition, it has become apparent that 20:5 3 has the same growth-enhancing effect as $22: 6 \omega 3$ and that both the highly unsaturated $\omega 3$ fatty acids have a biological efficiency or an EFA efficiency higher than that of $18: 3 \omega 3$.

These results also indicate that not only 18:3 33 , but also the other fatty acids of $\omega 3$ series, play a role as EFA for rainbow trout and that $\omega 3$ fatty acids above $C_{20}$ in chain

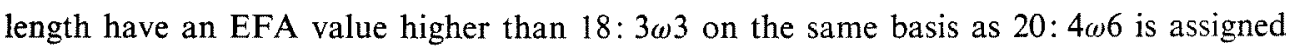
an EFA efficiency higher than that of $18: 2 \omega 6$ in mammals. ${ }^{7,81}$

\section{Acknowledgements}

We express here our sincere thanks to Dr. R. G. Ackman, Department of Environment, Fisheries and Marine Service, Halifax Laboratory, Canada and Dr. CHInkichi OGINo, Professor, Tokyo University of Fisheries, who kindly read the manuscript and gave valuable suggestions. Thanks are also due to Nagasaki Prefectural Fisheries Experimental Station which provided rotifers cultured with marine chlorella.

\section{References}

1) T. Watanabe and T. TakeuchI: This Bull. 42 893-906 (1976).

2) T. TAKEUCHI and T. WATANABE: ibid. 42, 907-919 (1976).

3) T. Watanabe, F. Takashima, and C. Ogino: ibid. 40 181-188 (1974).

4) J. Folch, M. Lees, and G. H. S. Stanley: J. Biol. Chem., 226, 497-507 (1957).

5) A. M. Abu-Nasr, W. M. Potts, and R. T. Holman: J. Am. Oil Chem. Soc., 31, 16-20 (1954).

6) T. TAKeuchi and T. Watanabe: This Bull, 43, 541-551 (1977).

7) R. B. Alfin-Slater and T. Kaneda: Federation Proc., 21, 285 (1962).

8) H. Mohrhauer and R. T. Holman: in "Lipid Pharmacology", (ed. by R. Paoletti), Academic Press, New York, 1964, p. 237.

\footnotetext{
* T. Takeuchi and T. Watanabe: Oral presentation at the annual meeting of Japan. Soc. Sci. Fish., in Shimonoseki, October, 1976.
} 